\title{
First International Workshop on Expressive Interactions for Sustainability and Empowerment (EISE 2009)
}

\author{
29 - 30 October 2009 \\ London, UK
}

Editors:

Prof. David Benyon

Dr Sriram Subramanian 


\section{Abstract}

The next generation of interactive technologies will be dominated by touch, gesture and other forms of movement. Collectively we refer to these as expressive interactions.

Tracking technologies are increasingly able to locate and follow people as they move through, or gesture in 3D space. Multi-touch surfaces and proximity sensing are set to be commonplace in business and leisure environments. New forms of 2D gestural interactions are emerging in different cultural settings. The next generation pico projectors promise to turn any surface into a re-configurable interactive device. Mobile devices enable expressive interactions with public displays changing the language and nature of interaction, particularly outside Europe and the USA.

The opportunities presented by these developments go far beyond iPhone apps, Wii games and photo applications on multi-touch tables. Large numbers of people who have previously been excluded from the digital economy have the potential to be empowered. The tyranny of the western keyboard and rectangular screen can be replaced by new forms of interaction that are much more intuitive and expressive. This in turn will democratize access to a wide range of new services, cutting across language, literacy and other barriers.

The technology drivers for this change come at an opportune moment for the world as it grapples with the sustainability agenda and enabling inclusivity. Interaction design must address the social, cultural, economic and environmental impact that it is having and develop methods to ensure sustainable designs. Technologies providing ubiquitous mobile access and intuitive interactions can be harnessed to enable a more inclusive approach, empowering people who are economically, educationally or physically challenged. Thus the digital economy can be opened up to a wider world. 


\section{Full Synopsis}

New technologies are changing the way people interact with each other across distances, geographies, cultures, and devices. In particular a new swath of technological innovation concerning expressive interaction is just beginning. These technologies emphasize touch and gesture over screen and keyboard. They involve ubiquitous, mobile interaction with large shared public surfaces. If designed thoughtfully the new forms of interaction that are enabled will lead to sustainable designs and empowered individuals.

It was the recognition of this imminent change in human-computer interaction that led to this first international workshop on Expressive Interaction for Sustainability and Empowerment, EISE. The workshop is supported by Interaction, a specialist group of the British Computer Society and hosted by Vodafone. There are eleven fully refereed contributions coming from three continents and two keynote lectures from industrialists promoting sustainability and technologies for empowering individuals in the twenty-first century.

In the first paper session on Inclusive Sustainability Lucia Terrenghi (Vodafone) and Sriram Subramanian from the University of Bristol argue for cultural sustainability and see the discipline of human-computer interaction $(\mathrm{HCl})$ as a natural home for this in interactive systems development. $\mathrm{HCl}$ needs to balance the local context and cultural diversity with the demands of global communication and the economic drive for standardisation. Anirhuda Joshi from IIT Bombay looks at economic sustainability and the use of mobile phones in India. He provides a rich and fascinating variety of case studies to illustrate three key themes of design for economic sustainability: creating a capacity to consume; high-tech and high-touch; rethinking ground up. In the third paper Rama Vennelakanti and Sriganesh Madhvanath (HP Labs, India) look at the context of a rapidly changing India and the impact this is having on new technologies and how they are developed. Opportunities for new devices to help with literacy and better communications between people are discussed.

Session 2 is concerned with gestures and mobility. Stephen Brewster and his colleagues from the University of Glasgow present a review of new interaction techniques that are becoming increasingly common thanks to miniaturisation of sensors and effectors. Gestures such as shaking, turning and waving are now available for interaction designers to make use of in new technologies. They also review the impact that sound, tactile feedback and proximity is having on human-computer interaction. Santanu Chaudhury and Aditya Khandelia (IIT Delhi) look at handwriting as an interface; something that remains one of the most basic and effective tools for communication. Kaustubh Srikrishna Patwardhan (IIT Bombay) and Sumantra Dutta Roy (IIT Delhi) focused on the technology for recognizing and tracking gestures in 3D space.

The third paper session is focused on case studies of expressive interaction. S Dey and Anupam Basu (IIT Kharagpur) and R. Mukherjee (ITME Kolkata) deal with the issue of the multiple languages that are spoken across the sub-continent. They describe a potable version of a proven augmentative and alternative communication tool called Sanyog. Melissa Loudon (University of Cape Town) and colleagues from the universities of Bristol and Southampton describe a system for measuring water quality utilizing mobile phone technology. The system keeps a 'human in the loop', resisting the takle over of all activities by technologies alone. In the tid paper Sunyoung Kim and Eric Paulos describe work in progress on building systems to detect and display air quality. 
The final session concerns near-end development. Alan Dix (University of Lancaster) with colleagues from HP Labs Bangalore and the National Institute of Design (Bangalore) explore the opportunities of delivering novel content to mobile phones. The unique difficulties of providing development environments for small mobile devices are discussed. Finally Peter Gall Krogh, Martin Ludvigsen and Marianne Graves Petersen (University of Aarhus) present their views on sustainability and interaction design. They present seven articles for sustainable design.

In addition to these papers, keynote talks were provided by Chris Burgess and Eric Shaffer and panel sessions were held to discuss the wide ranging issues involved in sustainability, empowering people particularly near to their place of work - and including them in the benefits that new technologies are providing.

Overall this first international workshop on expressive interaction for sustainability and empowerment has shown that there is a critical mass of people concerned and excited about the changing world of new technologies. The limited forms of interaction we have now (typically a key board and screen) are giving way to exciting new opportunities such as gesture, sound and touch. The aim of the EISE community is to harness these opportunities for the benefit of the widest range of people. We think that this first workshop is the first step along this new road. 


\section{Editors}

This conference was edited by:

Prof. David Benyon - Edinburgh Napier University,

http://www.cid.soc.napier.ac.uk/people/op/onepeople/peopleid/24

Dr Sriram Subramanian - University of Bristol, http://www.sriramsubramanian.com 


\section{Committee}

This conference was edited by:

\section{General Chair}

Tom McEwan Edinburgh Napier University, UK

\section{Technical Programme Chairs}

David Benyon Edinburgh Napier University, UK

Sriram Subramanian University of Bristol, UK

\section{Organisation Chair}

Lucia Terrenghi Vodafone

\section{Programme Committee Members}

Anupam Agrawal IIIT Allahabad, India

Stephen Brewster University of Glasgow, UK

Alan Dix Lancaster University, UK

Sumantra Dutta Roy IIT Delhi, India

Anirudha Joshi IIT Bombay, India

John Knight Vodafone

Ann Light Queen Mary University of London, UK

Sriganesh Madhvanath HP Labs, India

Tom McEwan Napier University, UK

Hema Murthy IIT Madras, India

Andy Smith Thames Valley University, UK

Lucia Terrenghi Vodafone 
Rama Vennelakanti HP Labs, India 


\section{Papers:}

\section{Session 1: Inclusive Sustainability}

\section{Keynote Paper}

Chris Burgess - Corporate Responsibility Director of Vodafone Why Would Vodafone Focus on Sustainability? (PDF) http://dx.doi.org/10.14236/ewic/EISE2009.1

Rama Vennelakanti and Sriganesh Madhvanath On-boarding the Next Billion: Issues, Approaches and Technologies for Expressive and Inclusive Interactions http://dx.doi.org/10.14236/ewic/EISE2009.2

Anirudha Joshi Mobile Phones and Economic Sustainability - Perspectives from India http://dx.doi.org/10.14236/ewic/EISE2009.3

Lucia Terrenghi and Sriram Subramanian Evolving the Role and Agenda of $\mathrm{HCl}$ for Sustainable Development http://dx.doi.org/10.14236/ewic/EISE2009.4

\section{Session 2: Gestures and Mobility}

Stephen Brewster, Roderick Murray-Smith, Andrew Crossan, Yolanda Vasquez-Alvarez and Julie Rico Multimodal Interactions for Expressive Interfaces http://dx.doi.org/10.14236/ewic/EISE2009.5

Santanu Chaudhury and Aditya Khandelia Handwriting Based Interface for Communication http://dx.doi.org/10.14236/ewic/EISE2009.6

Kaustubh Srikrishna Patwardhan and Sumantra Dutta Roy Modelling and Recognising Spatio-

Temporal Hand Gestures with an Uncalibrated Camera http://dx.doi.org/10.14236/ewic/EISE2009.7

\section{Session 3: Case Studies in Expressive Interactions}


Melissa Loudon, Tahmina Ajmal, Ulrike Rivett, Dirk de Jager, Robert Bain, Robert Matthews and Stephen Gundry A 'Human-in-the-Loop' Mobile Image Recognition Application for Rapid Scanning of Water Quality Test Results $\quad$ http://dx.doi.org/10.14236/ewic/EISE2009.8

S. Dey, R. Mukherjee and A. Basu Embedded Sanyog: a Portable Communication Tool for People with Multiple Disabilities $\quad$ http://dx.doi.org/10.14236/ewic/EISE2009.9

Sunyoung Kim and Eric Paulos Listening to Air Quality http://dx.doi.org/10.14236/ewic/EISE2009.10

\section{Session 4: Near-end Development for Empowerment}

\section{Keynote Paper}

Eric M Schaffer - CEO of Human Factors International Inc Sorry Engineers, but Sustainability Means Lifestyle Change (and only the psychologists can save us) (PDF) http://dx.doi.org/10.14236/ewic/EISE2009.11

Alan Dix, Ramesh Kozhissery, Ramprakash Ravichandran and Dinoop Dayanand Content Development Through the Keyhole http://dx.doi.org/10.14236/ewic/EISE2009.12

Peter Gall Krogh, Martin Ludvigsen and Marianne Graves Petersen Reconnecting actions and consequences http://dx.doi.org/10.14236/ewic/EISE2009.13 